\title{
Psychopathy and the DSM-IV Criteria for Antisocial Personality Disorder
}

\author{
Robert D. Hare \\ University of British Columbia \\ Stephen D. Hart \\ University of British Columbia \\ Timothy J. Harpur \\ University of British Columbia
}

\begin{abstract}
The Axis II Work Group of the Task Force on DSM-IV has expressed concern that antisocial personality disorder (APD) criteria are too long and cumbersome and that they focus on antisocial behaviors rather than personality traits central to traditional conceptions of psychopathy and to international criteria. We describe an alternative to the approach taken in the rev. 3rd ed. of the Diagnostic and Statistical Manual of Mental Disorders ( DSM - III - R ; American Psychiatric Association, 1987), namely, the revised Psychopathy Checklist. We also discuss the multisite APD field trials designed to evaluate and compare four criteria sets: the $D S M-I I I-R$ criteria, a shortened list of these criteria, the criteria for dyssocial personality disorder from the 10th ed. of the International Classification of Diseases ( World Health Organization, 1990), and a 10-item criteria set for psychopathic personality disorder derived from the revised Psychopathy Checklist.
\end{abstract}

The views expressed in this article are those of the authors and do not represent the official positions of the American Psychiatric Association or its Task Force on DSM-IV.

This work was supported by Grant MT-4511 from the Medical Research Council of Canada and by the Program of Research on Mental Health and the Law of the John D. and Catherine T. MacArthur Foundation.

We gratefully acknowledge the substantial contributions of Adelle E. Forth and Sherrie Williamson to the development of the psychopathic personality disorder criteria. We also appreciate the thoughtful comments made by Thomas A. Widiger and Scott Lilienfeld on an earlier draft of the article.

Timothy J. Harpur is now at the University of Illinois at Champaign.

Correspondence may be addressed to Robert D. Hare, Department of Psychology, University of British Columbia, 2136 West Mall, Vancouver, British Columbia, Canada, V6T 1 Y7.

Received: July 24, 1990

Revised: October 30, 1990

Accepted: December 17, 1990

The Axis II Work Group of the American Psychiatric Association's Task Force on DSM-IV (the fourth edition of the Diagnostic and Statistical Manual of Mental Disorders ) has identified antisocial personality disorder (APD) as "the personality disorder most likely to undergo major changes in 
$D S M-I V^{\prime \prime}$ ( American Psychiatric Association, 1990, p. 5). The goals of the work group are to "simplify the criteria for this disorder and at the same time include more traditional items, typical of psychopathy" (p. 6). As part of the second goal, the work group hopes to increase "congruency and compatibility" between the DSM-IV and criteria from the International Classification of Diseases and Related Health Problems (ICD-10; World Health Organization, 1990). The following four criteria sets have been developed for evaluation and comparison in field trials: the existing criteria in the revised DSM-III ( $D S M-I I I-R$; American Psychiatric Association, 1987 ) for APD (see Table 1); a shortened list of the $D S M-I I I-R$ criteria, developed by Lee Robins ( Table 2 ); the $I C D-10$ criteria for dyssocial personality disorder ( Table 3 ); and a set of diagnostic criteria for psychopathic personality disorder ( Table 4 ) derived from the Psychopathy Checklist—Revised (PCL—R; Hare, 1985a, 1991 ).

In this article we discuss the concerns that led the Axis II Work Group to consider making changes in the $D S M-I I I-R$ criteria for APD. Next, we describe alternative approaches to the $D S M-I I I-R$ criteria, focusing on the PCL-R. Finally, we comment briefly on the DSM-IV APD field trials, which are currently underway in five North American sites (and which are described by Widiger, Frances, Pincus, Davis, \& First, 1991 ).

\section{$D S M-I I I-R$ Criteria for Antisocial Personality Disorder}

Four criteria, singly necessary and jointly sufficient, are required for a $D S M-I I I-R$ diagnosis of APD (see Table 1 ): (a) the patient is at least 18 years old; (b) there is evidence of conduct problems before age 15 (at least 3 of 12 symptoms); (c) there is evidence of a pattern of antisocial behavior that persists into adulthood (at least 4 of 10 symptoms); and (d) antisocial behavior is not the result of (i.e., not exclusively during the course of) certain acute mental disorders, namely, schizophrenia or manic episodes.

One major criticism of the $D S M-I I I-R$ criteria for APD is that they are too long and cumbersome. The two inclusion criteria ( $b$ and c) take the form of fairly lengthy symptom checklists related to antisocial and delinquent behavior; in turn, most symptoms are defined in terms of a number of specific behavioral indicators. Consequently, the number of discrete clinical judgments required to diagnose APD is rather large. This has led to a concern that some clinicians may ignore the explicit APD criteria and rely instead on their own, idiosyncratic prototypical criteria ( Widiger, Frances, \& Trull, 1989). There is some empirical evidence to justify this concern (e.g., Ford \& Widiger, 1989; Morey \& Ochoa, 1989). Also, because such detailed information is required for a diagnosis, clinicians are generally forced to rely to a large extent on patients' memories and self-reports of their past conduct ( Widiger et al., 1989) -a state of affairs that is particularly problematic, given that untruthfulness is one of the disorder's symptoms (see Table 1 ). An obvious way to make the $D S M-I V$ criteria for APD more accessible to its users, then, is merely to shorten and simplify the existing $D S M-I I I-R$ criteria. This task was undertaken by Lee Robins, and the resulting criteria set is presented in Table 2 .

The $D S M-I I I-R$ approach to the diagnosis of APD is based on the assumption that personality traits are difficult to measure reliably and that it is easier to agree on the behaviors that typify a disorder than on the reasons why they occur ( Robins, 1978, p. 256). Although the result has been a diagnostic category with good reliability, concerns have been expressed about its content- and construct-related validity, in particular, about its relation to clinical conceptions of psychopathy, in which inferences about affective and interpersonal processes have long played an important role ( $\underline{\text { Hare, } 1983}$; $\underline{\text { Millon, } 1981 \text {; Wulach, }}$ 
1983 ). This is the second major criticism of the current $D S M-I I I-R$ criteria for APD: They represent a rather radical break with clinical tradition (see Cleckley, 1976; Karpman, 1961; McCord \& McCord, $\underline{1964}$; Millon, 1981 ), with clinical practice ( Davies \& Feldman, 1981; Gray \& Hutchison, 1964), with earlier versions of the $D S M$, and with international diagnostic nomenclature ( ICD-9 [ World Health Organization, 1978 ] and ICD-10 ; Sartorius, Jablensky, Cooper, \& Burke, 1988 ). Specifically, the $D S M-I I I-R$ criteria exclude, or at least do not explicitly include, such characteristics as selfishness, egocentricity, callousness, manipulativeness, lack of empathy, and so forth.

The lack of congruence between the $D S M-I I I-R$ criteria for APD and other well-established conceptions of psychopathy does not appear to have been intentional. Rather, this construct drift seems to have been the unforeseen result of reliance on a fixed (and possibly biased; see Millon, 1981) set of behavioral indicators in the DSM-III and the DSM-III-R. That is, the behavioral indicators do not provide adequate coverage of the construct they were designed to measure. As S. O. Lilienfeld (personal communication, September 15, 1990) pointed out, a diagnosis of APD is based largely on the use of closed concepts in which the diagnostician is required to select from a fixed and limited set of indicators of a trait; other, perhaps better indicators cannot be used. The use of closed concepts ignores the fact that a given trait can be reflected in a wide variety of behaviors and that a given behavior can reflect more than one personality trait ( Widiger et al., 1989). All of those who fulfill the APD criteria may be antisocial, but they may differ greatly in their motivations for being so and in significant interpersonal, affective, and psychopathological features, such as the capacity for empathy, remorse, guilt, anxiety, or loyalty. Paradoxically, the criteria for APD appear to define a diagnostic category that is at once too broad, encompassing criminals and antisocial persons who are psychologically heterogeneous, and too narrow, excluding those who have the personality structure of the psychopath but who have not exhibited some of the specific antisocial behaviors listed for APD ( Millon, 1981). 1 This second concern led to the inclusion of two criteria sets in the APD field trials that are closer to the the traditional clinical construct of psychopathy-the dyssocial and psychopathic personality disorder criteria ( Tables 3 and 4 ).

\section{An Alternative to Antisocial Personality Disorder: The Psychopathy Checklist-Revised}

Criticisms of the $D S M-I I I-R$ criteria for APD would be moot if there were no viable alternatives available. Over the last 10 years, however, a great deal of empirical evidence indicates that at least one viable alternative does exist-the PCL-R. The original PCL ( $\underline{\text { Hare, } 1980}$ ) was a 22-item clinical rating scale designed to assess the traditional clinical construct of psychopathy, perhaps best exemplified in the work of Cleckley (1976). More recently, a 20-item revision of the scale has been developed (PCL-R; $\underline{\text { Hare, } 1985 \mathrm{a}}, \underline{1991})$.

\section{Description}

The 20 items of the PCL-R (see Table 5 ) measure behaviors and inferred personality traits considered fundamental to the clinical construct of psychopathy. Most of the traits are treated as open concepts ( Lilienfeld, 1990 ). That is, the rater is provided with a description of a trait and with some behavioral exemplars and is asked to make a judgment about the extent to which a given person has the trait. Each item is scored on a 3-point scale, for which 0 indicates that it definitely does not apply, 1 that it applies somewhat or only in a limited sense, and 2 that it definitely does apply to the person. 
The information needed to score the items is obtained from a semistructured interview and institutional files. Detailed instructions for scoring the items are contained in the manual for the PCL-R ( Hare, 1991 ). Although clinical judgment and inference are required, the scoring criteria are quite explicit, and with some training, the items are not difficult to score.

\section{Descriptive Statistics and Reliability}

PCL-R total scores can range from 0 to 40 and represent the extent to which a person matches the prototypical psychopath. In most forensic samples the distribution of scores is approximately normal, with a slight negative skew. Although the total scores are dimensional, they can be used to provide a categorical diagnosis of psychopathy. A cutoff score of 30 has proven useful for this purpose.

Mean PCL-R scores are relatively consistent across samples of prison inmates and forensic patients from different institutions and countries. The mean total score for six samples of male prison inmates ( $N$ $=1,065)$ and four samples of male forensic patients $(N=440)$, described by Hare $(1991)$, is presented in Table 6.

Despite the subjective nature of most of the PCL $-\mathrm{R}$ items, each has reasonable interrater reliability (see Table 5 ). The internal consistency of the scale and the interrater reliability of total scores are high in samples of inmates and patients (see Table 6). (As values for inmates and patients were much the same, only combined data are presented).

\section{Factors}

There is strong evidence that the PCL- $\mathrm{R}$ consists of two stable, oblique factors ( Harpur, Hakstian, \& Hare, 1988 ). The correlation between the factors is about the same in samples of prison inmates (.56 on average) as it is in samples of forensic patients (.53 on average).

The items that define each factor are identified in Table 5 . Both factors are psychologically meaningful facets of the higher order construct of psychopathy. Factor 1 clearly reflects a set of interpersonal and affective characteristics, such as egocentricity, lack of remorse, callousness, and so forth, considered fundamental to clinical conceptions of psychopathy. In spite of the relatively small number (8) of items involved, Factor 1 scores, obtained by summing the individual item scores, are reliable in samples of prison inmates and forensic patients (see Table 2). Evidence presented elsewhere ( Hare, 1991; Harpur, Hare, \& Hakstian, 1989; Hart \& Hare, 1989) indicates that Factor 1 is positively correlated with clinical ratings of psychopathy, with prototypicality ratings of narcissistic and histrionic personality disorder, and with self-report measures of machiavellianism and narcissism. It is also negatively correlated with measures of empathy and anxiety.

Factor 2 reflects those aspects of psychopathy related to an impulsive, antisocial, and unstable lifestyle. It is positively correlated with diagnoses of APD, criminal behaviors, socioeconomic background, and self-report measures of socialization and antisocial behavior (

\section{Validity}

Evidence for the validity of the PCL and PCL-R is reviewed in detail elsewhere ( Hare, \& Harpur, in press ), and space limitations permit only a very brief outline of this evidence to be 
presented here. 2 When possible, we examine the comparative validity of the PCL $-\mathrm{R}$ and APD criteria.

\section{Content-related evidence.}

It is apparent from examination of the criteria sets (see Tables 1 and $\underline{5}$ ) and from our description of these criteria that the PCL $-\mathrm{R}$ provides more complete coverage of the traditional construct of psychopathy than do the APD criteria. The social deviance or antisociality facet of psychopathy is assessed reasonably well by both the APD criteria and by Factor 2 of the PCL-R, but APD neglects the facet of psychopathy assessed by PCL-R Factor 1.

\section{Concurrent criterion-related evidence.}

Total scores on the PCL and PCL-R are strongly related to other clinical-behavioral measures of psychopathy: Point-biserial correlations between total scores and $D S M-I I I$ or $D S M-I I I-R$ diagnoses of APD in eight samples of male offenders $(N=1,603)$ and in two samples of female offenders $(N=120)$ averaged about .55 ( $\underline{\text { Hare, } 1991}$ ); Factor 2 scores typically correlated higher with APD diagnoses than did Factor 1 scores (about .60 vs. .40).

Total scores are also correlated with various self-report measures related to psychopathy, including the Psychopathic Deviate and Hypomania scales of the Minnesota Multiphasic Personality Inventory, the California Psychological Inventory Socialization scale, and the Millon Clinical Multiaxial Inventory II Antisocial scale ( $\underline{\text { Hare, 1985b }}, \underline{1991}$; Harpur et al., 1989). However, the magnitude of these correlations typically is small (about .30-.35), as are the correlations between APD and self-reports ( Hare, 1985b ). In general, these self-report scales are more strongly correlated with Factor 2 than with Factor 1.

\section{Predictive criterion-related evidence.}

Hart, Kropp, and Hare (1988) found that the PCL predicted postrelease behavior in a sample of 231 federal offenders, even after they controlled for such variables as criminal history, previous conditional-release violations, and relevant demographic characteristics. Outcome (failure vs. success) correlated .33 with PCL total scores, .25 with PCL diagnoses of psychopathy and .20 with diagnoses of APD. Similar results were obtained by Serin, Peters, and Barbaree (in press) and by $\underline{\text { Serin (1990). }}$.

Harris, Rice, and Cormier (in press) reported that the PCL- $\mathrm{R}$ predicted postrelease violent offending in a sample of 169 male forensic patients. The violent recidivism rate for psychopaths (77\%) was almost four times that of nonpsychopaths (21\%). The PCL $-\mathrm{R}$ significantly improved the prediction of outcome over and above the use of criminal history variables and DSM-III diagnoses of APD. Violent recidivism correlated .42 with PCL-R total scores, .56 with PCL $-\mathrm{R}$ diagnoses of psychopathy, and .26 with diagnoses of APD.

In another study Rice, Harris, and Quinsey (1990) studied 54 rapists released from a maximum security psychiatric hospital. PCL-R total scores were significantly correlated with recidivism for violent offenses in general and with recidivism for sexual offenses in particular. A combination of PCL-R scores and a phallometric index of arousal (based on penile plethysmography) predicted recidivism as well as did a large battery of criminal history and demographic variables.

Ogloff, Wong, and Greenwood (1990) performed an outcome study of 80 men enrolled in a therapeutic community program designed to treat criminals with personality disorders. The data were prospective for 
some patients and retrospective for others, and the results indicated that PCL-R psychopaths remained in the program for a shorter period of time, put in less effort, and showed less improvement than did other inmates.

\section{Other construct-related evidence.}

Total scores typically correlate positively with scores on various measures of impulsivity, machiavellianism, narcissism, and sensation-seeking ( Hare, 1991; Harpur et al., 1989). Foreman (1988) found that PCL $-\mathrm{R}$ total scores $(N=79)$ were positively correlated $(r=.45)$ with staff ratings of dominance and negatively correlated $(r=-.46)$ with ratings of nurturance on the Interpersonal Adjective Scales ( Wiggins, Trapnell, \& Phillips, 1988 ).

The PCL-R shows good convergent and discriminant validity with respect to diagnoses of mental disorder. Hart and Hare (1989) found that PCL $-\mathrm{R}$ total scores were positively correlated with diagnoses of substance use disorder, histrionic personality disorder, and APD; they were also correlated with prototypicality ratings of histrionic personality disorder, narcissistic personality disorder, and APD. (Positive correlations between the PCL- R and substance use have also been reported by $\underline{\text { Smith \& }}$ Newman, 1990 .) Psychopaths were less likely than other patients to receive a DSM-III Axis I diagnosis (other than substance use disorder). PCL-R total and factor scores were either uncorrelated or negatively correlated with prototypicality ratings of schizophrenia and personality disorders (except histrionic, narcissistic, and antisocial, as noted earlier).

Further evidence of the discriminant validity of the PCL and PCL-R comes from studies with standardized psychological tests. Total scores are uncorrelated or negatively correlated with self-report measures of empathy, anxiety, depression, and general distress or neuroticism ( $\underline{\text { Hare, } 1991 \text {; Harpur et }}$ al., 1989; Hart, Forth, \& Hare, 1990). The results of over a dozen studies indicate that there is no association between total scores and performance on various intelligence tests ( $\underline{\text { Hare, } 1991}$ ). Also, two studies have reported that total scores are not associated with any impairment in performance on standard neuropsychological tests ( Hare, 1984 ; Hart, Forth, \& Hare, 1991).

The PCL and PCL-R have a strong and stable association with various indexes of criminality. Psychopaths are charged with a greater number and variety of criminal offenses than nonpsychopaths, regardless of race ( Kosson, Smith, \& Newman, 1990 ; Wong, 1984 ) or psychiatric status ( Hare, 1991; Hart \& Hare, 1989). Psychopaths commit violent and aggressive offenses at a particularly high rate. For example, in a sample of 244 inmates, Hare and McPherson (1984) found that PCL-defined psychopaths were significantly more likely than other criminals to engage in physical violence and other forms of aggressive behavior, including verbal abuse, threats, and intimidation, both in and out of prison.

Williamson, Hare, and Wong (1987) examined the nature of the violent offenses committed by psychopaths. Official police reports were used to analyze the circumstances of the most serious of inmates' instant offenses. Most of the murders and serious assaults committed by the nonpsychopaths occurred during a domestic dispute or during a period of extreme emotional arousal, whereas this was seldom true of the psychopaths. The victims of the nonpsychopaths were likely to be women and known to them, but the victims of the psychopaths were likely to be men and unknown to them. The violence of the psychopaths frequently had revenge or retribution as the motive or occurred during a drinking bout. In general, it appeared that most of the psychopaths' violence was callous and cold-blooded or part of an 
aggressive, macho display, without the affective coloring that accompanied the violence of nonpsychopaths.

Laboratory studies have generated a body of data that is theoretically meaningful with respect to psychopathy and that provides particularly important evidence for the construct validity of the PCL and PCL-R. For example, psychopathy is associated with abnormal processing of the affective components of language in a variety of laboratory tasks ( Williamson, Harpur, \& Hare, 1990, in press; see also review by Hare, Williamson, \& Harpur, 1988 ). Psychophysiological aspects of affective functioning in psychopaths have also been examined by Patrick and his colleagues ( Patrick, Bradley, \& Cuthbert, 1990 ; Patrick, Cuthbert, \& Lang, 1990). They have reported that psychopaths, defined with the PCL-R, gave smaller autonomic responses during fearful imagery than did other offenders and failed to show normal modulation of the blink reflex to an acoustic startle stimulus presented while slides with affective content were viewed. A third line of research has investigated Hare's (1982) hypothesis that psychopaths may be unusually proficient at selectively focusing attention on events that interest them. Several PCL and PCL $-\mathrm{R}$ studies have produced results that are generally consistent with the hypothesis (for a review, see Harpur \& Hare, 1990 ). Finally, Newman and his colleagues have published a series of studies of passive-avoidance learning, disinhibition, and dominant-response set in psychopaths, as defined by the PCL or PCL—R (e.g., Kosson \& Newman, 1986; Newman, Patterson, \& Kosson, 1987 ). Consistent with the theoretical model that underlies this research, there was general support for the hypothesis that the disinhibited behavior of psychopaths is related to a dominant-response set for reward.

\section{Summary}

The PCL-R assesses both the affective or interpersonal and the social deviance facets of psychopathy, whereas the $D S M-I I I-R$ focuses on the latter. The incremental validity obtained by including explicit inferences about key personality traits in the diagnosis of psychopathy is substantial, even when the criterion involves antisocial or criminal behaviors. This is an important point, given that the items that define APD are from much the same domain as, and therefore ought to predict, criterion variables related to criminality, violence, and recidivism. The fact that the PCL and PCL-R generally are more strongly related to these criterion variables than is APD attests to the value of including inferences about personality traits in the assessment of psychopathy. Equally important here is the evidence that laboratory tests of hypotheses about the nature of psychopathy are supported when assessment is based on the PCL or PCL-R. Although there is no similar body of systematic laboratory research on APD, several of the laboratory studies of psychopathy discussed above also obtained DSM-III or $D S M-I I I-R$ diagnoses of APD (C. J. Patrick, personal communication, October 23, 1990; Williamson et al., 1990, in press ). In each case, the effects that were significant with the PCL or PCL-R were not significant when the presence or absence of APD was the basis for group selection.

\section{Development of the Criteria Set for Psychopathic Personality Disorder}

The extensive evidence on the psychometric properties of the PCL $-\mathrm{R}$ clearly indicates that it is possible to obtain reliable and valid measures of the personality traits and behaviors associated with psychopathy. However, it is important to note that completion of the PCL $-\mathrm{R}$ requires a relatively long semistructured interview and access to a considerable amount of collateral information.

There is some evidence that the PCL $-\mathrm{R}$ can be shortened and simplified for clinical use without an unacceptable decrease in reliability or validity. As part of a large-scale study on the risk of violence in 
the mentally disordered, funded by the John D. and Catherine T MacArthur Foundation and directed by John Monahan (see Monahan, 1990), a 12-item screening version of the PCL-R (the PCL:SV; Hare, Cox, \& Hart, 1989) has been tested in seven samples (three prison, two forensic psychiatric, and two civil psychiatric). The items were designed to tap each of the PCL- $\mathrm{R}$ factors and are scored on the basis of a 30- to 45-min interview and minimal collateral information. Preliminary analyses of data from 331 subjects indicate that the PCL:SV has good psychometric properties. Thus, the average intraclass correlation coefficient (ICC) for a single rating and for the average of two ratings was about .80 and .85 , respectively. The average alpha coefficient was about .80 and the mean inter-item correlation (MIC) about .25. The correlation between independent ratings on the PCL:SV and the PCL-R averaged about .80 .

Encouraged by these results, we used the PCL-R and the PCL:SV as the basis for development of the 10-item criteria set for psychopathic personality disorder (PPD) presented in Table 4 . These items are substantively the same as those in the PCL:SV, and a reasonable reflection of the constructs measured by PCL-R Factors 1 and 2. Specific, though relatively brief, instructions are used to score each PPD item on a 3-point scale ( $2=$ item applies, $1=$ item applies somewhat, or evidence is mixed, $0=$ item does not apply). Total scores can range from 0 to 20 and represent the extent to which the person matches the clinical prototype of the psychopath.

Despite the advantages that dimensional ratings have in clinical research and practice, $D S M-I V$ plans to continue using simple categorical diagnoses. On the basis of some preliminary analyses, we determined that a diagnosis of PPD must require that 7 of the 10 criteria be satisfied (i.e., scored 2). We estimate that it will yield a base rate for psychopathy of about 25\%-30\% among federal prisoners and about $15 \%$ among forensic psychiatric inpatients; these values are similar to those obtained with the PCL $-\mathrm{R}$ and PCL:SV, and less than one-half the prevalence of APD. $\underline{3}$

\section{DSM-IV Field Trials}

As we noted earlier, Widiger et al. (1991) describe the APD field trials in some detail. Briefly, they noted that the four criteria sets presented in Tables 1 to $\underline{4}$ will be tested at five different sites. At each site approximately 100 patients (total $N=500$ ) will be administered structured interviews and subsequently assessed with all four criteria sets, wherein about half of subjects will receive an independent reassessment at a later date. This will allow a determination of the interrater reliability, internal consistency, concurrent validity, and coverage of the various criteria sets. In addition, self-report, demographic, and psychosocial history data will be collected to evaluate the construct validity of the criteria sets. If no single criteria set is clearly superior to the others, the Task Force may test various combinations of symptoms from the different criteria sets.

We concur with Widiger et al. (1991) that these field trials represent a significant advance over committee or expert consensus approaches to decision making with respect to the content of diagnostic criteria: "The results will not be unambiguous with respect to which criteria set is preferable, but the field trial will provide reliability and validity data that will be informative for their evaluation, and together with the results provided by the literature review and data reanalyses, the study will facilitate the effort to have the decisions of the work group be empirically based" (pp. 286). Perhaps the biggest strength of the field trials is the attempt made to sample subjects from diverse populations (e.g., prisoners, psychiatric inpatients, substance abusers, and adopted-away offspring), so that reliability and validity data can be compared across various settings. 
Of course, a single study-even a large, multicenter study-cannot answer all the relevant questions. An important limitation of the field trials is that they will be unable to examine some important aspects of validity, for example, predictive validity with respect to criminal behavior, or experimental validity with respect to psychophysiological or cognitive variables. (As noted earlier, it is in precisely these areas that the PCL and PCL-R approach appears superior to APD.) Full evaluation of the construct validity of the criteria sets will be a lengthy (and, some may argue, a never-ending) process, however, and we recognize that the publication of the $D S M-I V$ is a practical necessity that cannot be postponed indefinitely.

\section{Concluding Comments}

Despite the successes of the $D S M-I I I$ and $D S M-I I I-R$ APD criteria, conceptual and empirical arguments exist for evaluating alternative approaches to the assessment of psychopathy. The field trials described are an important-but not final-step in this direction, and the data collected may play a crucial role in the selection of the $D S M-I V$ APD criteria. However, our hope is that the information presented here will stimulate further research on the comparative validity of diagnostic criteria for psychopathy; although too late to influence $D S M-I V$, this research may well play a decisive role in subsequent versions or revisions of the DSM.

\section{References}

American Psychiatric Association. (1987). Diagnostic and statistical manual of mental disorders (Rev.3rd ed.).(Washington DC: Author) American Psychiatric Association. (1990, January/February). DSM-IV Update. (Washington, DC: Author)

Cleckley, H. (1976). The mask of sanity (5th ed.).(St. Louis MO: Mosby)

Correctional Service of Canada. (1990). A mental health profile of federally sentenced offenders. Forum on Corrections Research, 2, 7-8.

Davies, W. \& Feldman, P. (1981). The diagnosis of psychopathy by forensic specialists. British Journal of Psychiatry, 138, 329-331.

Ford, M. R. \& Widiger, T. A. (1989). Sex bias in the diagnosis of histrionic and antisocial personality disorders. Journal of Consulting and Clinical Psychology, 57, 301-305.

Foreman, M. (1988). Psychopathy and interpersonal behavior. (Unpublished doctoral dissertation, University of British Columbia, Vancouver, Canada)

Gray, K. C. \& Hutchison, H. C. (1964). The psychopathic personality: A survey of Canadian psychiatrists' opinions. Canadian Psychiatric Association Journal, 9, 452-461.

Hare, R. D. (1980). A research scale for the assessment of psychopathy in criminal populations. Personality and Individual Differences, 1, 111-117.

Hare, R. D. (1982). Psychopathy and physiological activity during anticipation of an aversive stimulus in a distraction paradigm. Psychophysiology, 19, 266-271.

Hare, R. D. (1983). Diagnosis of antisocial personality disorder in two prison populations. American Journal of Psychiatry, 140, 887-890.

Hare, R. D. (1984). Performance of psychopaths on cognitive tasks related to frontal-lobe functioning. Journal of Abnormal Psychology, 93, 133-140.

Hare, R. D. (1985a). Comparison of procedures for the assessment of psychopathy. Journal of 
Consulting and Clinical Psychology, 53, 7-16.

Hare, R. D. (1985b). The Psychopathy Checklist. (Unpublished manuscript, University of British Columbia, Vancouver, Canada)

Hare, R. D. (1991). The Hare Psychopathy Checklist—Revised. (Toronto: Multi-Health Systems) Hare, R. D., Cox, D. N. \& Hart, S. D. (1989). Preliminary manual for the Psychopathy

Checklist-Screening Version (PCL-SV). (Unpublished manuscript, University of British Columbia, Vancouver, Canada)

Hare, R. D., Harpur, T. J., Hakstian, A. R., Forth, A. E., Hart, S. D. \& Newman, J. P. (1990). The revised Psychopathy Checklist: Reliability and factor structure. Psychological Assessment: A Journal of Consulting and Clinical Psychology, 2, 338-341.

Hare, R. D. \& McPherson, L. M. (1984). Violent and aggressive behavior by criminal psychopaths. International Journal of Law and Psychiatry, 7, 35-50.

Hare, R. D., Williamson, S. E. \& Harpur, T. J. (1988). Psychopathy and language.(In T. E. Moffitt \& S. A. Mednick (Eds.), Biological contributions to crime causation (pp. 68-92). Dordrecht, the

Netherlands: Martinus Nijhoff.)

Harpur, T. J., Hakstian, A. R. \& Hare, R. D. (1988). Factor structure of the Psychopathy Checklist. Journal of Consulting and Clinical Psychology, 56, 741-747.

Harpur, T. J. \& Hare, R. D. (1990). Psychopathy and attention.(In J. Enns (Ed.), The development of attention: Research and theory (pp. 429—444). New York: North Holland.)

Harpur, T. J., Hare, R. D. \& Hakstian, A. R. (1989). Two-factor conceptualization of psychopathy: Construct validity and assessment implications. Psychological Assessment: A Journal of Consulting and Clinical Psychology, 1, 6-17.

Harpur, T. J., Hare, R. D., Zimmerman, M. \& Coryell, W. (1990, August). Dimensions underlying DSM-III personality disorders: Cluster 2.(Paper presented at the 98th Annual Convention of the American Psychological Association, Boston, MA)

Harris, G. T., Rice, M. E. \& Cormier, C (in press). Psychopathy and violent recidivism.(Law and Human Behavior. )

Hart, S. D., Forth, A. E. \& Hare, R. D. (1990). Performance of male psychopaths on selected neuropsychological tests. Journal of Abnormal Psychology, 99, 374-379.

Hart, S. D. \& Hare, R. D. (1989). Discriminant validity of the Psychopathy Checklist in a forensic psychiatric population. Psychological Assessment: A Journal of Consulting and Clinical Psychology, 1, 211-218.

Hart, S. D., Hare, R. D. \& Harpur, T. J. (in press). The Psychopathy Checklist: An overview for researchers and clinicians.(In J. Rosen \& P. McReynolds (Eds.), Advances in psychological assessment (Vol. 8). New York: Plenum Press.)

Hart, S. D., Kropp, P. R. \& Hare, R. D. (1988). Performance of male psychopaths following conditional release from prison. Journal of Consulting and Clinical Psychology, 56, 227-232.

Karpman, B. (1961). The structure of neurosis: With special differentials between neurosis, psychosis, homosexuality, alcoholism, psychopathy, and criminality. Archives of Criminal Psychodynamics, 4, 599-646.

Kosson, D. S. \& Newman, J. P. (1986). Psychopathy and allocation of attentional capacity in a divided-attention situation. Journal of Abnormal Psychology, 95, 257-263.

Kosson, D. S., Smith, S. S. \& Newman, J. P. (1990). Evaluation of the construct validity of psychopathy in Black and White male inmates: Three preliminary studies. Journal of Abnormal Psychology, 99, 250-259.

Lilienfeld, S. O. (1990). Conceptual and empirical issues in the assessment of psychopathy. 
(Unpublished manuscript, University of Albany, State University of New York)

McCord, W. \& McCord, J. (1964). The psychopath: An essay on the criminal mind. (Princeton, NJ: Van Nostrand)

Millon, T. (1981). Disorders of personality: DSM-III, Axis II.(New York: Wiley)

Monahan, J. (1990). Risk of violence among the mentally disordered: A description of the MacArthur Risk Study. (Unpublished manuscript, University of Virginia School of Law, Charlottesville, VA) Morey, L. C. (1988). The categorical representation of personality disorder: A cluster analysis of DSM-III Personality features. Journal of Abnormal Psychology, 97, 314-321.

Morey, L. C. \& Ochoa, E. S. (1989). An investigation of adherence to diagnostic criteria: Clinical diagnosis of the DSM-III personality disorders. Journal of Personality Disorders, 3, 180-192. Newman, J. P., Patterson, C. M. \& Kosson, D. S. (1987). Response perseveration in psychopaths. Journal of Abnormal Psychology, 96, 145-148.

Ogloff, J. P. R., Wong, S. \& Greenwood, A. (1990). Treating criminal psychopaths in a therapeutic community program. Behavioral Sciences and the Law, 8, 81-90.

Patrick, C. J., Bradley, M. \& Cuthbert, B. N. (1990). The criminal psychopath and startle modulation. Psychophysiology, 72, (suppl. 4a) S7

Patrick, C. J., Cuthbert, B. N. \& Lang, P. J. (1990). Emotion in the criminal psychopath: Fear imagery. Psychophysiology, 27, (suppl. 4a) S55

Rice, M. E., Harris, G. T. \& Quinsey, V. L. (1990). A follow-up of rapists assessed in a maximum security psychiatric facility. Journal of Interpersonal Violence, 4, 435-448.

Robins, L. N. (1978). Etiological implications in childhood histories relating to antisocial personality.(In R. D. Hare \& D. Schalling (Eds.), Psychopathic behavior: Approaches to research (pp. 255-272). Chichester, United Kingdom: Wiley.)

Sartorius, N., Jablensky, A., Cooper, J. E. \& Burke, J. D. (Eds.) (1988). Psychiatric classification in an international perspective.(The British Journal of Psychiatry 152 (Suppl. 1).)

Serin, R.C. (in press). Psychopathy and violence in criminals.(Journal of Interpersonal Violence. ) Serin, R., Peters, R. D. \& Barbaree, H. E. (1990). Predictors of psychopathy and release outcome in a criminal population. Psychological Assessment: A Journal of Consulting and Clinical Psychology, 2, 419-422.

Smith, S. S. \& Newman, J. P. (1990). Alcohol and drug abuse-dependence disorders in psychopathic and nonpsychopathic criminal offenders. Journal of Abnormal Psychology, 99, 430-439.

Widiger, T. A., Frances, A. J. \& Trull, T. J. (1989). Personality disorders.(In R. J. Craig (Ed.), Clinical and diagnostic interviewing (pp. 221-236). Northvale, NJ: Jason Aronson.)

Widiger, T. A., Frances, A. J., Pincus, H. A., Davis, W. W. \& First, M. (1991). Toward an empirical classification for DSM-IV. Journal of Abnormal Psychology, 100, 280-288.

Wiggins, J. S., Trapnell, P. \& Phillips, N. (1988). Psychometric and geometric characteristics of the Revised Interpersonal Adjective Scale (IAS-R). Multivariate Behavioral Research, 23, 517-530. Williamson, S., Hare, R. D. \& Wong, S. (1987). Violence: Criminal psychopaths and their victims. Canadian Journal of Behavioral Science, 19, 454-462.

Williamson, S., Harpur, T. J. \& Hare, R. D. (in press). Abnormal processing of affective words by psychopaths. Psychophysiology., ,

Williamson, S., Harpur, T. J. \& Hare, R. D. (1990, August). Sensitivity to emotional valence in psychopaths. (Paper presented at the 98th Annual Convention of the American Psychological Association, Boston, M)

Wong, S. (1984). Criminal and institutional behaviors of psychopaths.(Programs Branch Users Report. Ottawa, Ontario, Canada: Ministry of the Solicitor-General of Canada.) 
World Health Organization. (1978). International classification of diseases, injuries and causes of death (9th ed.).(Geneva: Author)

World Health Organization. (1990). International classification of diseases and related health problems (10th ed.).(Geneva: Author)

Wulach, J. (1983). Diagnosing the DSM-III antisocial personality disorder. Professional Psychology: Research and Practice, 14, 330-340.

\section{1}

It is worth noting here that the $D S M-I I I$ and $D S M-I I I-R$ antisocial personality disorder symptoms lack internal consistency and do not appear to form a natural cluster. Rather, some of the antisocial personality disorder symptoms covary with certain symptoms of narcissistic personality disorder-such as exploitativeness, grandiosity, and a lack of empathy-to form a syndrome very similar to the traditional clinical construct of psychopathy ( $\underline{\text { Harpur, Hare, Zimmerman, \& Coryell, 1990; }}$ Morey, 1988 ).

\section{2}

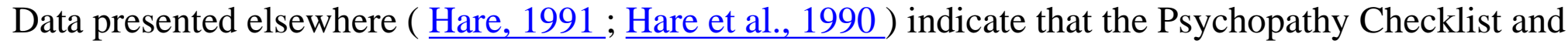
its revision are highly correlated and can be considered measures of the same construct. For this reason, we do not distinguish between the two scales in our review of validity-related evidence.

3

A recent study by the Correctional Service of Canada (1990) found that approximately $75 \%$ of the male inmates in Canadian federal prisons met the criteria for antisocial personality disorder.

Table 1.

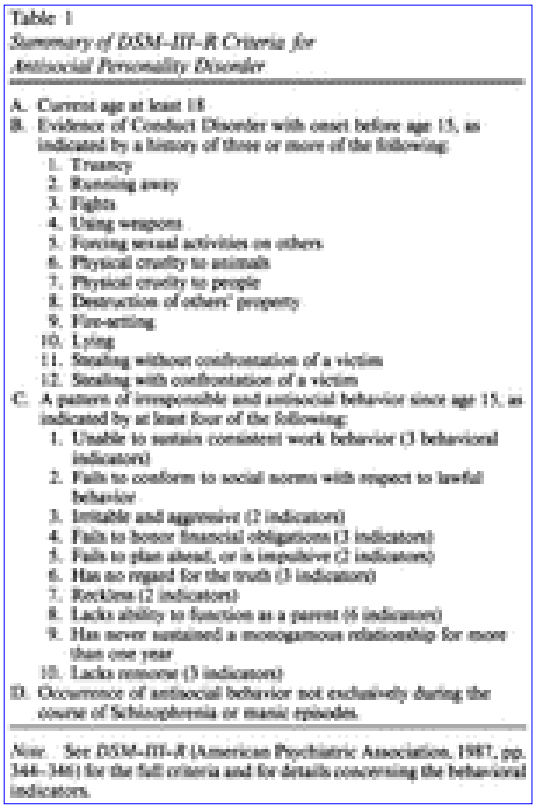




\section{Table 2.}

\begin{tabular}{|c|c|}
\hline & 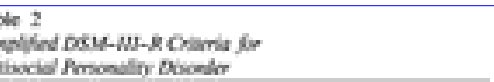 \\
\hline & 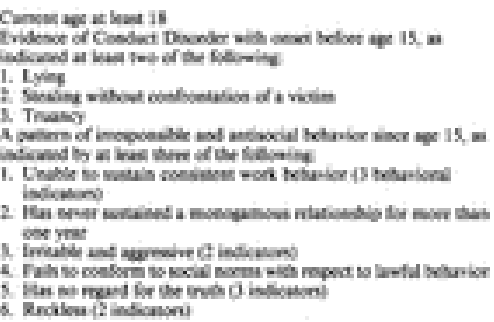 \\
\hline
\end{tabular}

\section{Table 3.}

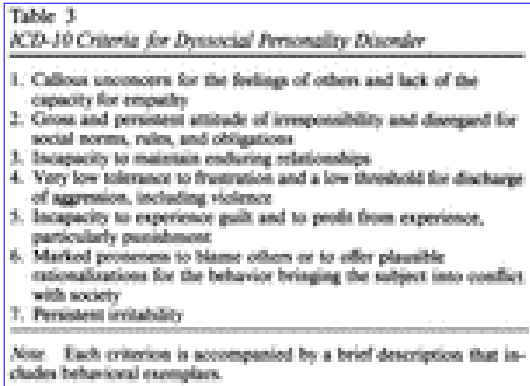

\section{Table 4.}

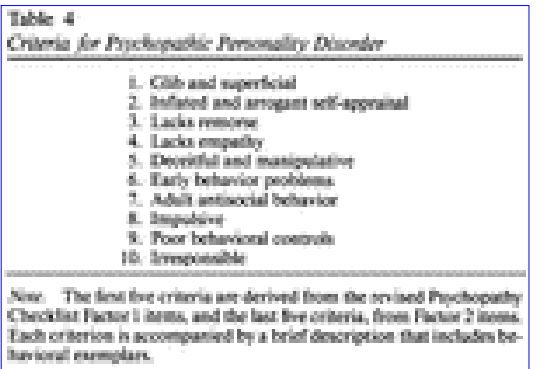

\section{Table 5.}

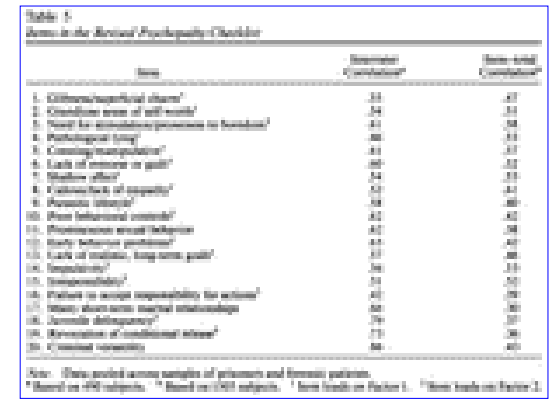




\section{Table 6.}

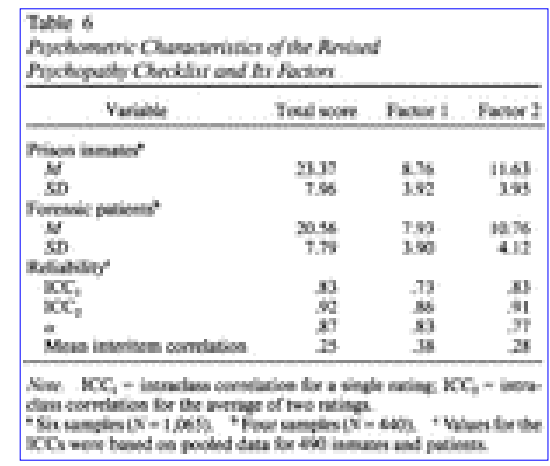

